\title{
Fluorinated Ketjen-black as Cathode Material for Lithium Primary Batteries
}

\author{
Shengbo Jiang ${ }^{1}$, Ping Huang ${ }^{1}$, Jiachun Lu ${ }^{1}$, Zhichao Liu ${ }^{1}$ \\ ${ }^{1}$ Northwest Institute of Nuclear Technology, P.O. Box 69-14, Xi' an 710024, P.R. China
}

\begin{abstract}
Lithium/fluorinated carbon $\left(\mathrm{Li} / \mathrm{CF}_{\mathrm{x}}\right)$ batteries are the highest-energy-density primary batteries which are widely used in various field. Herein, the novel fluorinated carbon $\left(\mathrm{CF}_{\mathrm{x}}\right)$ with superior performance are made of fluorination of ketjen-black. The fluorinated ketjen-black (F-KB) as the cathode material of $\mathrm{Li} / \mathrm{CF}_{\mathrm{x}}$ delivered a high specific capacity over $880 \mathrm{mAh} \mathrm{g}^{-1}$ with a discharge plateau $\sim 3.1 \mathrm{~V}\left(\mathrm{vs}^{\mathrm{Li}} \mathrm{Li}^{+} / \mathrm{Li}\right)$. The energy density over $2400 \mathrm{Wh} \mathrm{kg}^{-1}$ for F-KB is higher than the theoretical energy density $\left(2180 \mathrm{Wh} \mathrm{kg}^{-1}\right)$ of fluorinated graphite. F-KB can be discharged at high rate of 5C delivering a high-power density of $9710 \mathrm{~W}$ $\mathrm{kg}^{-1}$ with the energy density of $1610 \mathrm{Wh} \mathrm{kg}^{-1}$, showing good performance of rate capability.
\end{abstract}

\section{Introduction}

As is known to all, the solid-state lithium primary batteries have the highest specific energy. Fluorinated carbons $\left(\mathrm{CF}_{\mathrm{x}}\right)$ used as the cathode of the lithium primary batteries have a very high theoretical energy densities $\left(2180 \mathrm{Wh} \mathrm{kg}^{-1}\right.$ with $\mathrm{x}=1$ for fluorinated graphite)[1] comparing with other primary lithium batteries such as $\mathrm{Li} / \mathrm{SOCl}_{2}\left(1470 \mathrm{Wh} \mathrm{kg}^{-}\right.$ $\left.{ }^{1}\right)$ batteries and $\mathrm{Li} / \mathrm{MnO}_{2}\left(1005 \mathrm{Wh} \mathrm{kg}^{-1}\right)$ batteries[2]. Due to the advantage of theoretical energy densities, a wide operating temperature, long storage life, reliability, and so on[3], lithium/fluorinated carbon $\left(\mathrm{Li} / \mathrm{CF}_{\mathrm{x}}\right)$ batteries have been widely used in many civil and military applications[4]. Despite the intriguing merits of $\mathrm{Li} / \mathrm{CF}_{\mathrm{x}}$ batteries, the weak intrinsic conductivity of $\mathrm{CF}_{\mathrm{x}}$ and high polarizability of $\mathrm{Li} / \mathrm{CF}_{\mathrm{x}}$ cell impeded the practical application[5]. Been considered to be one of the most important factors for poor rate performance of $\mathrm{Li} / \mathrm{CF}_{\mathrm{x}}$ batteries, the poor conductivity makes the actual capacity lower than the theoretical for $\mathrm{Li} / \mathrm{CF}_{\mathrm{x}}$ batteries and the initial voltage delay[6]. Consequently, various efforts have been used to enhance the conductivity of $\mathrm{CF}_{\mathrm{x}}$ compounds for improving the electrochemical performance of $\mathrm{Li} / \mathrm{CF}_{\mathrm{x}}$ batteries.

In this study, a fluorinated ketjen-black(F-KB) was prepared by a direct gas fluorination of ketjen-black. As the cathode material in $\mathrm{Li} / \mathrm{CF}_{\mathrm{x}}$ batteries, the $\mathrm{F}-\mathrm{KB}$ has a high energy density over $2400 \mathrm{Wh} \mathrm{kg}^{-1}$ higher than the theoretical value $\left(2180 \mathrm{Wh} \mathrm{kg}^{-1}\right)$ of fluorinated graphite. The maximum power density for $\mathrm{Li} / \mathrm{CF}_{\mathrm{x}}$ could be as high as $9710 \mathrm{~W} \mathrm{~kg}^{-1}$ (F-KB) with the energy density of 1610 $\mathrm{Wh} \mathrm{kg}^{-1}$ showing good performance of rate capability.

\section{Experimental}

\subsection{Material synthesis}

Ketjen-black was directly purchased from Japan Lion Specialty Chemicals Co., Ltd. Before the fluorination, the ketjen-black was dried at $200{ }^{\circ} \mathrm{C}$ for 2 hours in vacuum. After the drying, the kejten-black was fluorinated in a pure nickel reactor using pure $\mathrm{NF}_{3}$ gas at temperature of $510{ }^{\circ} \mathrm{C}$ by 5 hours. The fluorinated products named as F-KB. Fluorinated graphite (FG) was purchased from Japan Daikin Industries, Ltd.

\subsection{Material characterization}

FT-IR spectra was performed using an infrared spectrometer (a PerkinElmer Frontier FT-IR). XRD was studied by conventional powder X-ray diffraction (Bruker-AXS D8 Advance X-Ray Diffractometer) with $\mathrm{CuK} \alpha$ radiation. XPS analysis was measured with a spectrometer (PERKINELMZRPHI 3056) with an Al anode source operated at $15 \mathrm{kV}$. TG-DSC of materials was performed on SDT Q600 V8.0 Build 95 heated to $800{ }^{\circ} \mathrm{C}$ in $\mathrm{N}_{2}$ at a rate of $10{ }^{\circ} \mathrm{C} \mathrm{min}^{-1}$. The $\mathrm{N}_{2}$ adsorption/desorption isotherms and Brunauer-EmmettTeller (BET) surface area was measured using an Autosorb-iQ instrument.

\subsection{Electrochemical measurements}

The cathode was papered by fluorinated compounds, acetylene black, polyvinylidene fluoride (PVDF) in a weight ratio of $8: 1: 1$. The fluorinated compounds were F$\mathrm{KB}$ and graphite fluorides (GF; Daikin. Japan) respectively. Each cathode comprises the active materials loading as between 1.5 and $2 \mathrm{mg} \mathrm{cm}^{-2}$. Li metal disks were the anodes of Coin cells (CR2032), Celgard 2400 membrane was used as a separator and 1.0 M LiBF4 in propylene carbonate/dimethoxy ethane (PC/DME, 1:1 vol) was used as the electrolyte. Discharge tests at various currents were measured with a LAND CT2001A.The 
battery test system at $25^{\circ} \mathrm{C}$, and the cut-off voltage was 1.5 V.

\section{Results and discussions}

\section{1 structural characterization}

The chemical structures of kejten-black, fluorinated graphite (FG,) and fluorinated kejten-black (F-KB) were studied by the Fourier-transform infrared (FT-IR) spectra, and the spectra are showing in Fig.1. There were no obvious absorption peaks for KB in the FT-IR spectra, indicating no oxygen-containing organic groups in KB. The FG and F-KB exhibit intense band at the wavenumber of $1196 \mathrm{~cm}^{-1}$, which is the stretching vibration of covalent $\mathrm{C}-\mathrm{F}$ bond. The FT-IR spectra shows that the strength of C$\mathrm{F}$ bond of $\mathrm{FG}$ is stronger than $\mathrm{C}-\mathrm{F}$ bond of $\mathrm{F}-\mathrm{KB}$. The band existed at around the wavenumber of $1330 \mathrm{~cm}^{-1}$ indicated the existence of $-\mathrm{CF}_{2}$ groups. There are no obvious absorption peaks for FG in the FT-IR spectra at about wavenumber of $1100 \mathrm{~cm}^{-1}$ because of the low content of semi-ionic C-F bands. But, the semi-ionic C-F bonds are existed in the chemical structure of F-KB duo to the absorption peaks for F-KB in the FT-IR spectra at about $1100 \mathrm{~cm}-1$. The $-\mathrm{CF}_{3}$ groups are still found because of the absorption peaks for FG and F-KB in the FT-IR spectra at about $670 \mathrm{~cm}^{-1}$.

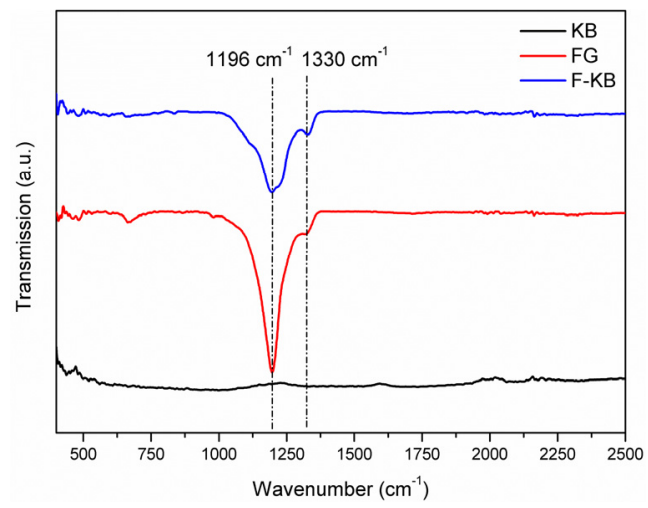

Fig1. FT-IR images of KB, FG and F-KB

The XRD patterns of KB, FG and F-KB are showing in the Fig.2. The tow diffraction peaks of KB located at

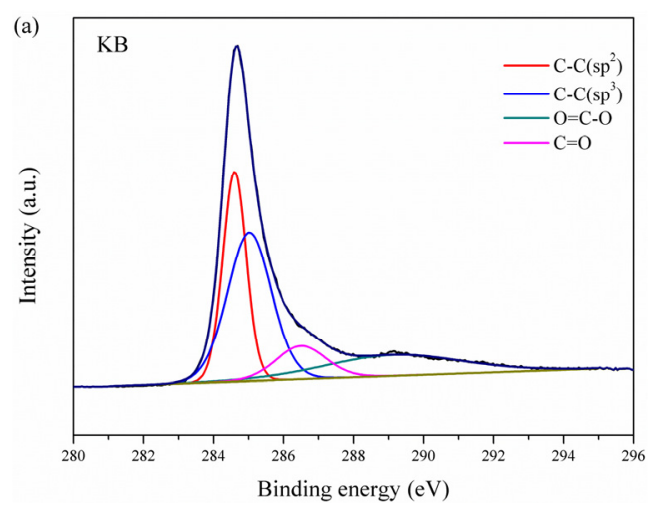

(a) $\mathrm{C} 1 \mathrm{~s}$ of $\mathrm{KB}$ nearly $24^{\circ}$ and $43^{\circ}$, responding to (002) and (100) reflection of graphite structure. This signified that there are some graphic domains stacking in the pristine $\mathrm{KB}$. Using the Bragg equation, the (002) layer spacing of KB is calculated to be $0.370 \mathrm{~nm}$ which is bigger than the theoretical value of graphite $(0.335 \mathrm{~nm})$.After fluorination, the new phase of F-KB appears according to the diffraction peaks at $12.6^{\circ}$ and $41^{\circ}$ attributed to the diffraction of (001) and (100) lattice plane of fluorinated graphite, which means the graphic structure in pristine KB were destroyed by $\mathrm{NF}_{3}$ molecules at high temperature.

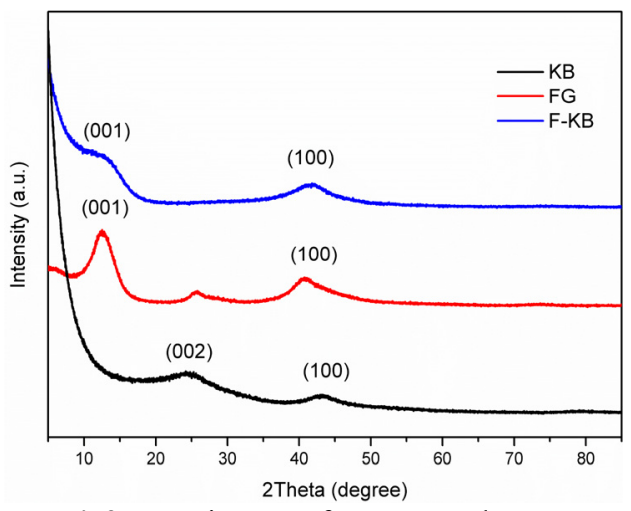

Fig2. XRD images of $\mathrm{KB}, \mathrm{FG}$ and $\mathrm{F}-\mathrm{KB}$

The chemical states of $\mathrm{C}$ elements for $\mathrm{KB}, \mathrm{FG}$ and $\mathrm{F}$ $\mathrm{KB}$ are analysed by high resolution XPS (shown in Fig.3). There are four different states of carbon species fitting to the $\mathrm{C} 1 \mathrm{~s}$ spectrum of $\mathrm{KB}$ at binding energy of $\sim 284.6 \mathrm{eV}$ for $\mathrm{sp}^{2}$-type C-C, $\sim 285.02 \mathrm{eV}$ for $\mathrm{sp}^{3}$-type C-C, 286.5 $\mathrm{eV}$ for $\mathrm{C}=\mathrm{O}$ and $\sim 289.1 \mathrm{eV}$ for $\mathrm{O}=\mathrm{C}-\mathrm{O}[7]$. After the fluorination, the $\mathrm{O}=\mathrm{C}=\mathrm{O}$ disappears and many $\mathrm{C}=\mathrm{C}$ bands changes to $\mathrm{C}-\mathrm{F}$ bonds. The $\mathrm{C}=\mathrm{C}$ bond still exist in the XPS spectra of $\mathrm{F}-\mathrm{KB}$ means that the carbon atoms are not completely fluorinated. The big difference between the XPS spectra of FG and F-KB is that there are semi-ionic $\mathrm{C}-\mathrm{F}$ bond peaks for F-KB located at binding energy of $286.8 \mathrm{eV}$, which is consistent with the FT-IR analysis. Previous studies have shown that semi-ionic C-F bonds could effectively improve electron transport and the rate capability of $\mathrm{Li} / \mathrm{CF}_{\mathrm{x}}$ batteries[8].

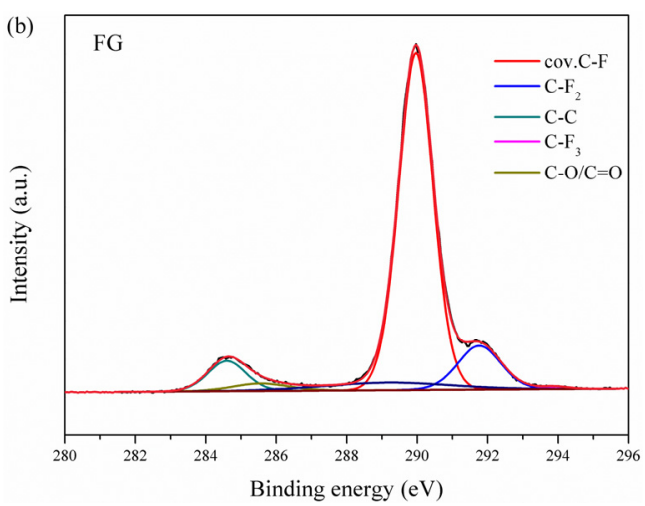

(b) $\mathrm{C} 1 \mathrm{~s}$ of $\mathrm{FG}$ 


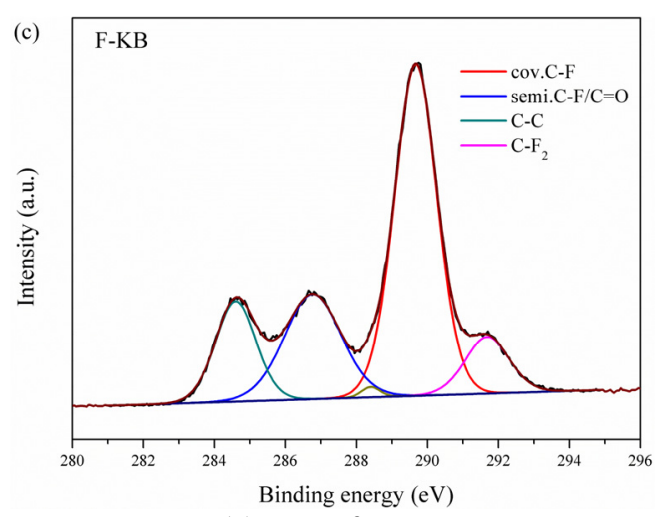

(c) $\mathrm{C} 1 \mathrm{~s}$ of $\mathrm{F}-\mathrm{KB}$

Fig3. High resolution $\mathrm{C} 1$ s spectra of $\mathrm{KB}, \mathrm{FG}$ and F-KB

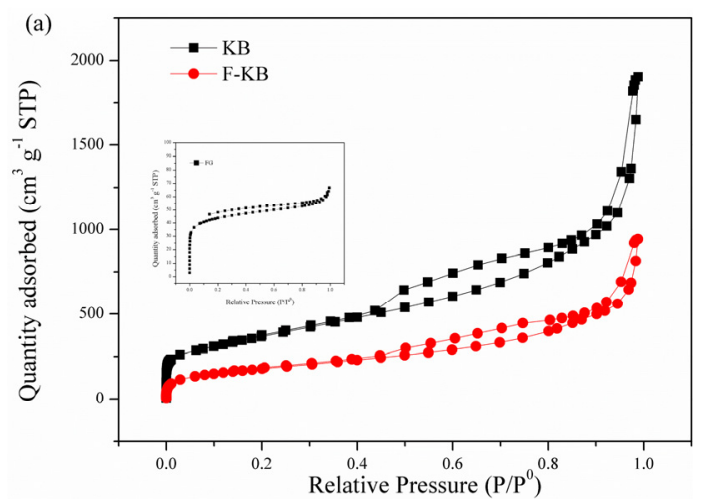

(a) Nitrogen isotherms

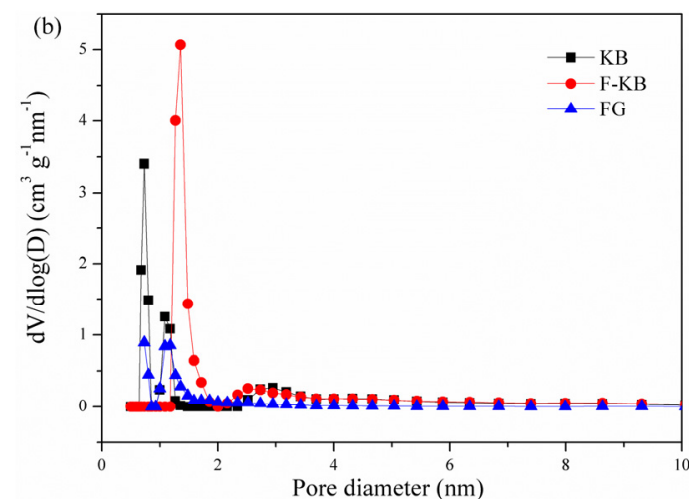

(b) Pore size distributions

Fig4. Nitrogen isotherms and pore size distributions of KB, FG and F-KB

The surface characterizations of $\mathrm{KB}$ and $\mathrm{F}-\mathrm{KB}$ as shown in Fig.4 were measured using Brunauer-EmmettTeller (BET) method. The $\mathrm{N}_{2}$ adsorption-desorption isotherm of $\mathrm{KB}$ and $\mathrm{F}-\mathrm{KB}$ could be classified as type IV, which means that the structures have large amount of micropores and mesopores. The specific surface areas for $\mathrm{KB}, \mathrm{F}-\mathrm{KB}$ and FG were measured to be $1321.4 \mathrm{~m}^{2} \mathrm{~g}^{-1}$, $651.7 \mathrm{~cm}^{2} \mathrm{~g}^{-1}$ and $144.8 \mathrm{~cm}^{2} \mathrm{~g}^{-1}$ respectively. The pose sizes of the $\mathrm{KB}, \mathrm{FKB}$ and $\mathrm{FG}$ are analysed based on

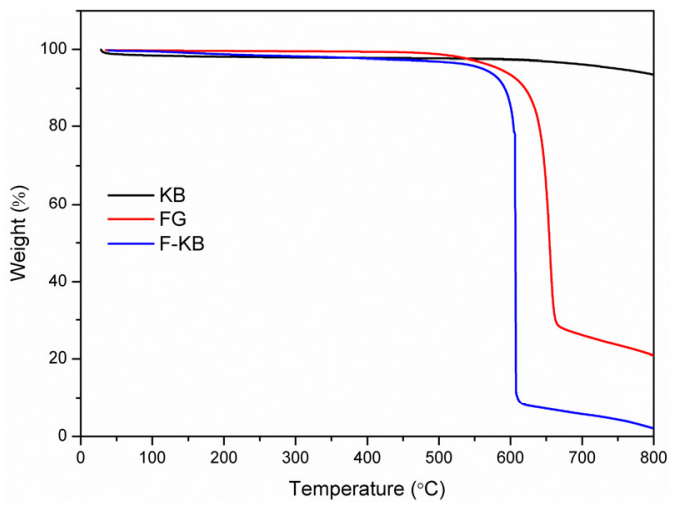

(a) DSC images of KB, FG and F-KB nonlocalized density functional theory (NLDFT). The micropores were enlarged and the mesopores still existed by fluorination which might promote lithium ion transfer.

As showing in Fig.5, the TG-DSC were used to test the thermal stabilities of KB, FG and F-KB under $\mathrm{N}_{2}$ atmosphere. The decomposition of F-KB starts at $570.0^{\circ} \mathrm{C}$, which is lower than $618.9^{\circ} \mathrm{C}$ for $\mathrm{FG}$. The result suggests that the C-F bond of F-KB is much weaker than that of FG, which is agree with the results obtained by FT-IR.

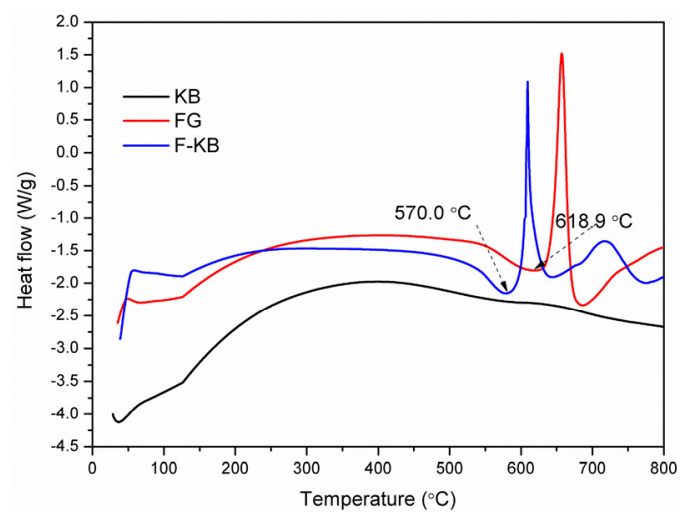

(b) TG images of KB, FG and F-KB

Fig5. Thermal analysis of KB, FG and F-KB 


\subsection{Electrochemical performance}

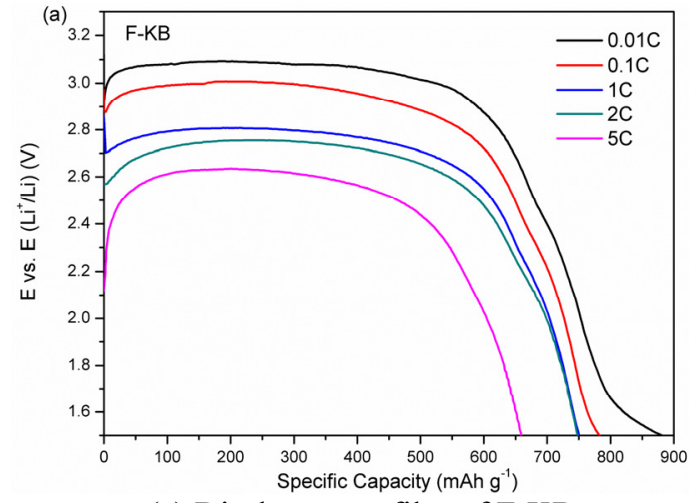

(a) Discharge profiles of F-KB

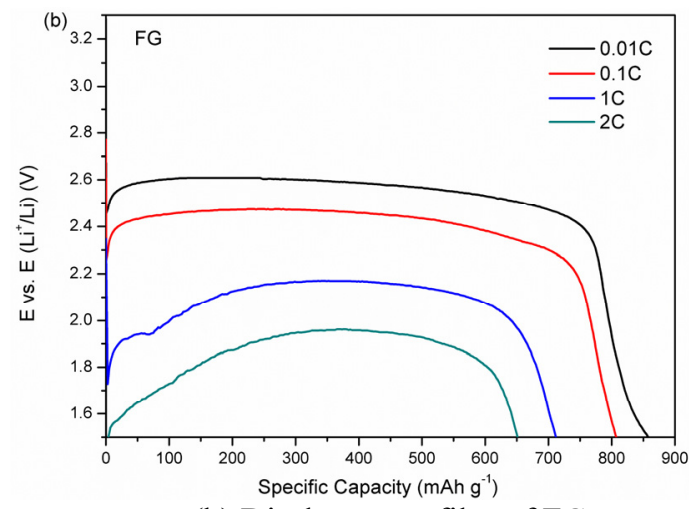

(b) Discharge profiles of FG

Fig6. Galvanostatic discharge profiles of F-KB and FG at different current densities

The electrochemical performance of F-KB and FG as cathode materials of $\mathrm{Li} / \mathrm{CF}_{\mathrm{x}}$ batteries investigated at different discharge rate with a potential cut-off of $1.5 \mathrm{~V}$ are showing in Fig.6. The F-KB material delivers a specific capacity of $880 \mathrm{mAh} \mathrm{g}^{-1}$ with a discharge plateau $\sim 3.1 \mathrm{~V}$ at $0.01 \mathrm{C}$, which is better than $850 \mathrm{mAh}$ $\mathrm{g}^{-1}$ with a discharge plateau $\sim 2.6 \mathrm{~V}$ for FG. The specific capacity of F-KB was higher than its theoretical values probably because of the side reactions of intermediates with electrolyte components. The energy density for F-KB up to $2400 \mathrm{Wh} \mathrm{kg}^{-1}$ is much better than $2130 \mathrm{Wh} \mathrm{kg}^{-1}$ for $\mathrm{FG}$ at $0.01 \mathrm{C}$. With the discharge rate increases, the voltage hysteresis for F-KB is superior to that for FG. When the discharge rate is over $2 \mathrm{C}, \mathrm{FG}$ as the cathode materials of $\mathrm{Li} / \mathrm{CF}_{\mathrm{x}}$ cannot give off electricity. But the F-KB still maintain very good electrochemical performance. Due to the part of the carbon atoms with fluorine atoms in the form of $\mathrm{sp}^{2}$ hybridization combination and the nonfluorinated carbon atoms which maintain the original porous structure, enhanced the conductivity of fluoride products and improved the lithium ion diffusion rate, the rate capability of $\mathrm{F}-\mathrm{KB}$ as the cathode of $\mathrm{Li} / \mathrm{CF}_{\mathrm{x}}$ batteries have been greatly improved. Comparable to fluorinated nanotubes and nanofibers, F-KB as the cathode material has a specific capacity of $650 \mathrm{mAh} \mathrm{g}^{-1}$ with a discharge plateau $\sim 2.6 \mathrm{~V}$, and the maximum power density is up to $9710 \mathrm{~W} \mathrm{~kg}^{-1}$ at $5 \mathrm{C}$.

\section{Conclusions}

The fluorinated ketjen-black (F-KB) has been papered through direct fluorination with $\mathrm{NF}_{3}$ gas and ketjen-black at $510{ }^{\circ} \mathrm{C}$. The structural feature of $\mathrm{F}-\mathrm{KB}$ displays that large layer spacing, the certain amount of semi-ionic C-F and huge number of micropores and mesopores facilitated electron and lithium ion transfer. The F-KB as cathode material of $\mathrm{Li} / \mathrm{CF}_{\mathrm{x}}$ batteries has excellent electrochemical performance. The F-KB possesses the maximum energy density over $2400 \mathrm{Wh} \mathrm{kg}^{-1}$ at discharge rate of $0.01 \mathrm{C}$. The maximum power density for $\mathrm{Li} / \mathrm{CF}_{\mathrm{x}}$ could be as high as $9710 \mathrm{~W} \mathrm{~kg}^{-1}$ (F-KB) with the energy density of $1610 \mathrm{Wh}$ $\mathrm{kg}^{-1}$ at discharge rate of $5 \mathrm{C}$. The high specific capacity and excellent power density make the F-KB material has the potential to become a cathode material for $\mathrm{Li} / \mathrm{CF}_{\mathrm{x}}$ batteries.

\section{References}

1. Shao, Y., et al., Synthesis and Reaction Mechanism of Novel Fluorinated Carbon Fiber as a High-Voltage Cathode Material for Rechargeable $\mathrm{Na}$ Batteries. Chemistry of Materials, 2016. 28(4): p. 1026-1033.

2. Ma, Y., et al., Lithium Sulfur Primary Battery with Super High Energy Density: Based on the Cauliflower-like Structured C/S Cathode. Scientific Reports, 2015. 5(1): p. 14949.

3. Jayasinghe, R., et al., Optimization of Multi-Walled Carbon Nanotube based CFx electrodes for improved primary and secondary battery performances. Journal of Power Sources, 2014. 253: p. 404-411.

4. Guérin, K., et al., Applicative performances of fluorinated carbons through fluorination routes: A review. Journal of Fluorine Chemistry, 2012. 134: p. 11-17.

5. Ahmad, Y., et al., Pushing the theoretical limit of LiCFx batteries using fluorinated nanostructured carbon nanodiscs. Carbon, 2015. 94: p. 1061-1070.

6. Makotchenko, V.G., et al., The synthesis and properties of highly exfoliated graphites from fluorinated graphite intercalation compounds. Carbon, 2011. 49(10): p. 3233-3241.

7. Cheng, L., et al., Partially Fluorinated Graphene: Structural and Electrical Characterization. ACS Applied Materials \& Interfaces, 2016. 8(7): p. 50025008.

8. Zhou, R., et al., The electrochemical performances of fluorinated hard carbon as the cathode of lithium primary batteries. Composites Communications, 2020. 21: p. 100396. 